12 million E.P.U. units of account and, including research, would require a staff not exceeding 400-450.

The Steering Committee expects shortly to submit proposals for the joint construction or operation of two experimental reactor projects (boiling water reactor and homogeneous aqueous reactor) and is also to report shortly on the measures at present under discussion for liberalization of international trade. It is also to submit proposals regarding training, and particularly the assistance to be given to universities and higher technical colleges of member countries for training specialists; health and safety, particularly the examination of projects for the discharge of radioactive waste, the evaluation of reactor hazards, and the international transport of highly radioactive materials; and liability and transport, particularly the drawing up of common rules concerning third-party liability in the nuclear field. Annexes to the report include a general description of the recommended processing plant, the text of the proposed conventions and the amended Statute of the Study Group, as well as the proposals of the working groups on experimental reactors and on nuclear power stations for their co-operative development in Europe. There is also a summary of the national programmes for building nuclear power stations in Austria, Belgium, France, Western Germany, Italy, the Netherlands, Sweden, Switzerlanrl and the United Kingdom.

On the basis of this report, the Council, on December 17, 1957, adopted the Statute of the European Nuclear Energy Agency, and the International Convention on Security Control was signed by mem. ber countries of the Organization for European Economic Co-operation on December 20. The text of this Statute and the Convention (see Nature, 181, $952 ; 1958$ ) are also appended to the report, which, with the details of membership of the study groups, working groups and working parties and of the Steering Committee itself, is a particularly useful reference document on the present development of nuclear energy in Europe.

\title{
THE TASMANIAN MUTTON-BIRD
}

$\mathrm{T}$ HE Tasmanian mutton-bird, Puffinus tenuirostris (Temminek), is known to ornithologists as the short-tailed or slender-billed shearwater, and was known to the 'Tasmanian aborigines as 'yolla' and to the white seafarers of Bass Strait as the 'yowler'. Historically it is recorded earlier than white settlement of Australia; sociologically it has importance as the only example of commercial wildfowling successfully surviving in Australia and in being the mainstay of that interesting community, the Cape Barren Islanders ; scientifically, it amazes naturalists through the astonishing regularity of its breeding time-table, its widespread migration and its uncannily accurate homing each year to its exact nesting site. It also occurs in such abundance that it could quite well be Australia's most numerous bird. An interesting account of the bird has been prepared by D. L. Serventy*.

Puffinus tenuirostris is a long-lived bird, and, for its size, has an unusually lengthy period of sexual immaturity. Female birds begin to breed at 5-7 years of age and males at 7-8 years. Immature birds do not make a landfall, once they leave their natal islands as fledglings, until they are 3-4 years of age.

The sexually mature, breeding birds return from their migration to the nesting islands in the last week of September, and by then gametogenesis is well advanced. Burrows are actively scratched out, and vocal performances enliven the rookeries at night. Though egg-laying does not begin until the third week in November, a striking behavioural change occurs at the beginning of November. The birds vacate the islands entirely, and do not return again until the onset of egg-laying.

The exodus follows immediately after fertilization, and the birds leave for the open sea while the single very large egg matures (it weighs about $85 \mathrm{gm}$. and is about 16 per cent of the female's body-weight). Though this pre-egg-laying exodus was known in the Tasmanian mutton-bird from early times, it was not detected in other petrels until comparatively lately.

*A Ast. Mus. Mag., 12, No. 10 (June 15, 1958).
Egg-laying starts about November 20-22 and encts about November 30-December 2. The calendar is invariable from year to year and from rookery to rookery, though these are spread through eleven degrees of latitude-from near Ceduna, in South Australia, to southern Tasmania-adjacent to seas which differ widely in temperature, chemical composition and currents. Year-to-year variations in the local sea conditions, or the weather, have no influence on the breeding calendar, which is the same now as when the earliest observers wrote their accounts more? than a hundred years ago. This surprising constaney has yet to be fully explained.

When the birds return to their nesting islands for the egg-laying the male gonad has dwindled drastically in size, and the seminiferous tubules are in a state of fatty metamorphosis. No other avian species shows a more rapid collapse of the testis, though this may be characteristic of the petrel group. When the egg is laid, the female departs to the sea to recuperate.

The newly hatched chick is rarely tended continuously by the parents for longer than two days and is then left alone by day. Both parents share in the feeding, which takes place at intervals, and the young bird may have to undergo lengthy fasts of several days between Gargantuan banquets of krill. The growth-rate is rapid and the fledgling may come to exceed the weight of a large adult in little more than a month after hatching. The young birds emerge, from the burrows at night, vigorously exercise their wings and at length make their own departure from the natal islands. This exodus of the fledglings usually occurs from the third week in April to the first week in May.

The nature of this migration has long been a matter of speculation. Some ornithologists were loath to believe that the birds in the northern Pacific could be of the same breeding stock as the Australian birds. The first ornithologist to suggest that the north Pacific birds were Australian birds on migration was A. J. Campbell. It was only in 1955 
that the first positive proof was obtained by a banding record.

The route followed on migration appears to be largely conditioned by the direction and strength of the prevailing winds. By flying a roundabout 'figure of eight' course over the Pacific the birds are assisted by wind. The only place where they meet with any strong wind resistance is on the southward leg of the route when returning to Australia in the spring. Here they have to battle against the strong southeast trade winds which blow all the year round across the Pacific. Wherever they cross this belt the birds encounter strong winds.

These youthful first- and second-year birds share in the general migration of the more mature birds, though some individuals among them may continue to spend the southern summer in the north. Such behaviour is not unusual with other trans-equatorial migrants, such as the waders. Even though they may migrate south with the breeding birds, the first-and second-year individuals do not come ashore but remain at sea. It is only when they reach three years of age that they effect a landfall, and then only comparatively briefly, between hatching time in January and the third week in March. The fourthyear birds show a similar behaviour, but more appear to come ashore at this age than at three years, and some individuals even put in an appearance earlier in the season, namely, from mid-December onwards. When they are five years and older the birds appear to come ashore with the breeding adults, though they remain unmated.

Once a bird begins to breed on a particular site, it tends to return to the same spot each season with remarkable fidelity. Often it remains mated with the same partner. On Fisher Island there are several examples of birds which have bred together each year since observations first began in 1947.

\title{
AN ANTIBONDING MORSE POTENTIAL
}

\author{
BY ROBERT W. KEYES
}

Westinghouse Research Laboratories, Pittsburgh 35, Pennsylvania

$\mathrm{M}$

ORSE has proposed a three-parameter function, $\mu(r)=L[\exp \{-2 \beta(r-a)\}-2 \exp \{-\beta(r-a)\}]$

to represent the potential function for the motion of the nuclei of a diatomic molecule ${ }^{1}$. The function (1) has proved quite useful in the understanding of the properties of diatomic molecules, since Morse was able to solve the one-dimensional Schrödinger equation for motion in the potential $\mu(r)$, and thus to express the molecular energy-levels in terms of the parameters $L, \beta$ and $a$.

I wish to suggest how the potential for the antibonding state corresponding to (1) can be represented by a similar function. Compare function (1) with a one-electron system in which the quantum mechanical theory easily leads to an approximate analytical formula for the potential for nuclear motion, namely, the hydrogen molecule ion. In the approximation in which the wave function is considered to be a linear combination of atomic $1 s$ functions and the Coulombic field of the second nucleus is considered as a perturbation, the potential in question is :

$$
\mu(r)=\mathrm{f}(r) \exp (-2 r / b)-\mathrm{g}(r) \exp (-r / b)
$$

where $f(r)$ and $g(r)$ are algebraic functions of $r$, the distance between the two protons, and $b$ is the Bohr radius $^{2}$.

Now, in (2) we assume that the important dependence on $r$ arises from the variation of the exponentials, rather than of the algebraic functions. That is, we make the approximations $\mathrm{f}(r)=f_{0}$ and $\mathrm{g}(r)=g_{0}$, where $f_{0}$ and $g_{0}$ are constants. It is then found that the minimum of the potential (2) occurs at $r=c=$ $b \log \left(2 f_{0} / g_{0}\right)$, and that (2) can be written :

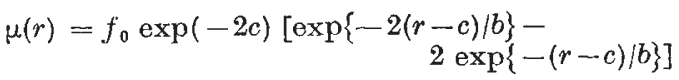

But (3) is the same as (1) with $\mathrm{L}=f_{0} \exp (-2 c)$, $\beta=1 / b$, and $a=c$.

Thus, it is seen that the first and second terms of the Morse potential (1) correspond to the first and second terms of (2), respectively. The theory ${ }^{2}$, however, reveals the physical origin of the terms of (2). The first term arises from Coulombic interactions of the protons and electron, and is always repulsive. The second term arises from the resonance or exchange integral, and, for the state in question, is attractive. Thus, we identify the first and second terms of the Morse potential with the Coulombic and exchange effects, respectively.

The usefulness of this interpretation arises from the fact that the potential function for the antibonding electronic state of the hydrogen molecule ion differs from the bonding state only in the sign of the exchange integral, except for an orthogonality correction $^{2}$. Thus we would expect that the potential for the antibonding electronic state arising from the atomic functions which give rise to (1) can be approximately written as :

$$
\mu_{a b}(r)=L[\exp \{-2 \beta(r-b)\}+2 \exp \{-\beta(r-b)\}]
$$

The validity of the approximations involved in the use of (4) to represent the antibonding potential is checked in Fig. 1, where the bonding and antibonding potentials given by the simple perturbation theory for orbitals composed of linear combinations of atomic $1 s$ functions for the hydrogen molecule ion are plotted as solid lines. A Morse function (1) can be chosen to give a quite good fit to the bonding potential. The fact that the algebraic functions $f(r)$ and $\mathrm{g}(r)$ have been replaced by constants shows up in that the value of $\beta$ which gives the best fit of (1) to (2) is not exactly $1 / b$. According to (4), the antibonding potential corresponding to (1) can be obtained by simply changing the sign of the second term of (1). This antibonding potential is also plotted in Fig. 1 as a dashed line, and is seen to be a good approximation to the result of the perturbation theory.

In a system in which many electrons contribute to the bond between two atoms, in general the contribution of some of the electrons to the bonding potential will be bonding and the contribution of 